\title{
Caracterización del Traumatismo Dentoalveolar que Afecta a los Tejidos de Soporte en Dientes Temporales
}

\author{
Characterization of Dentoalveolar Trauma that Affects \\ the Supporting Tissues in Primary Teeth
}

Claudia Ávila Rivera; Alfredo Cueto Urbina \& Jenniffer González Ríos

\begin{abstract}
ÁVILA, R. C.; CUETO, U. A. \& GONZÁLEZ, R. J. Caracterización del traumatismo dentoalveolar que afecta a los tejidos de soporte en dientes temporales. Int. J. Odontostomat., 6(2):157-161, 2012.

RESUMEN: El propósito de esta investigación es describir la distribución del traumatismo dentoalveolar en dientes temporales según género, edad, etiología, lugar donde ocurre el traumatismo, diagnóstico de traumatismo, dientes más afectados y tratamiento realizado. La muestra comprende 207 niños beneficiarios del Centro de referencia Odontopediátrico Simón Bolívar, de edades entre 1 a 7 años, que sufrieron traumatismo dentoalveolar del sector anterior dentario, durante los años 2005-2007 que corresponde según la clasificación propuesta por Andreasen, a lesiones que afectan al tejido de soporte dentario, lesiones incluídas: subluxación, luxación lateral, luxación intrusiva, luxación extrusiva y avulsión. Los resultados obtenidos nos permiten observar un mayor porcentaje de traumatismos en el género masculino con un $60 \%$, siendo la edad más frecuente entre 4 y 6 años, los incisivos centrales superiores son los dientes más afectados (39-40\%). La etiología más común corresponde a caída con un $25 \%$, siendo más prevalente en el colegio o jardín infantil (20\%). El diagnóstico del traumatismo dentoalveolar de mayor frecuencia corresponde a subluxación presentándose en el $53 \%$ de los casos. El control e indicaciones es el tratamiento más realizado en estos traumatismos dentoalveolares.
\end{abstract}

PALABRAS CLAVE: trauma dentoalveolar, dentición primaria.

\section{INTRODUCCIÓN}

El traumatismo dentoalveolar (TDA) es uno de los accidentes más dramáticos que le sucede a un niño, siendo considerados un problema de salud pública, debido a que se calcula que, aproximadamente el $30 \%$ de niños menores de 6 años, han sufrido un TDA en su dentición primaria. En consecuencia, existe una alta frecuencia de lesiones debiendo el odontólogo enfrentase a este tipo de consultas de urgencias, siendo más frecuentes las lesiones que afectan los tejidos de soporte dentario, debido a las distintas características del periodonto, entre éstas, presenta un hueso alveolar menos denso y mineralizado, con amplios espacios medulares y un ligamento periodontal más elástico entregándole mayor flexibilidad a los tejidos.

Es relevante para el odontólogo, en especial de los Servicios de Salud, conocer el perfil de los niños con TDA, tratarlos oportunamente y evitar las secuelas que pueden afectar los dientes definitivos, el propósito que persigue este estudio, es caracterizar el TDA que afecta las estructuras de soporte de los dientes temporales y los tratamientos a los cuales fueron sometidos los niños que lo padecieron.

\section{MATERIAL Y MÉTODO}

El estudio realizado corresponde a un diseño epidemiológico de tipo transversal. La población en estudio fueron niños en edades entre los 1 a 7 años que sufrieron TDA a los tejidos de soporte de dientes anteriores temporales y que acudieron al Centro de referencia Odontopediátrico Simón Bolívar, entre los años 2005 y 2007 . Dicho servicio atiende a preescolares y escolares de la comuna de Viña del Mar, a través de un programa de promoción prevención, diagnóstico y tratamiento buco dentario. La recogida de datos se realizó en base a lo consignado en las fichas clínicas de estos pacientes, aquellas fichas incompletas se excluyeron del estudio. 
En este estudio se censó todos los casos atendidos por diagnóstico de traumatismo dentoalveolar, que afectaron las estructuras de soporte de dientes anteriores temporales, de niños entre 1 a 7 años de edad para el período referido para su estudio se aplicó la clasificación propuesta por Andreasen, para las lesiones que afectan al tejido de soporte dentario, incluyéndose: subluxación, luxación lateral, luxación intrusiva, luxación extrusiva y avulsión.

Se considero subluxación aquella lesión de las estructuras de soporte del diente en la que existe dolor a la percusión y movilidad pero no existe desplazamiento del diente. Luxación lateral, aquella en la que existe desplazamiento del diente en una dirección distinta a la axial ya sea hacia palatino o lingual. Luxación intrusiva, como aquel desplazamiento del diente hacia el interior del hueso alveolar. Luxación extrusiva, desplazamiento del diente fuera de su alvéolo. Finalmente se consideró avulsión cuando el diente era desplazado completamente fuera de su alvéolo.

En el estudio se recogieron las siguientes variables: género, edad, etiología del TDA, lugar donde ocurrió el TDA, diagnóstico del tipo de TDA, tratamiento realizado y dientes afectados. En la variable etiología del TDA, se consideraron las siguientes alternativas caída, golpe contra objeto, caída en bicicleta- patineta - scooter, choque contra terceras personas, otros (accidentes de tránsito y violencia) y no especificado (aquellos casos no registrados en las fichas clínicas). En cuanto al lugar del TDA, se consideraron caída estando en la casa, calle, colegio-jardín infantilguarderías, y no especificado. En el caso del tratamiento se consideraron las acciones clínicas realizadas por los profesionales del Centro entre éstas: indicaciones como maniobra terapéutica, cuando éstas estaban dadas por escrito a los tutores, las cuales se enfocaban principalmente a una buena higiene oral con un cepillo blando, alimentación semisólida por 15 días, uso de enjuagatorio o gel de clorhexidina después del cepillado, eliminar uso de chupete o mamadera y consultar con el odontó- logo frente a cualquier complicación que presente el paciente; medicación, que incluye la prescripción de analgésicos, antibiótico y/o antiinflamatorio; ferulización comprende aquél procedimiento que trata de dar estabilidad al diente traumatizado utilizando un dispositivo flexible o semiflexible, adherido mediante composite a los dientes vecinos y exodoncia implica la extracción del diente. En aquellos casos en los que no se indicaba en la ficha clínica el procedimiento efectuado, se consideró como no especificado.

Se utilizaron programas computacionales: Microsoft Excel 2007 y Minitab 15 y R-Cran 2.13 para el análisis de los datos.

\section{RESULTADOS}

Se excluyeron 6 fichas clínicas cuyos registros no proporcionaban la información completa equivalente al $2,8 \%$ de los casos.

En nuestro estudio la distribución del TDA que afecta los Tejidos de Soporte de los dientes Temporales (TSDT) por género muestra una mayor frecuencia de $60 \%$ por el sexo masculino.

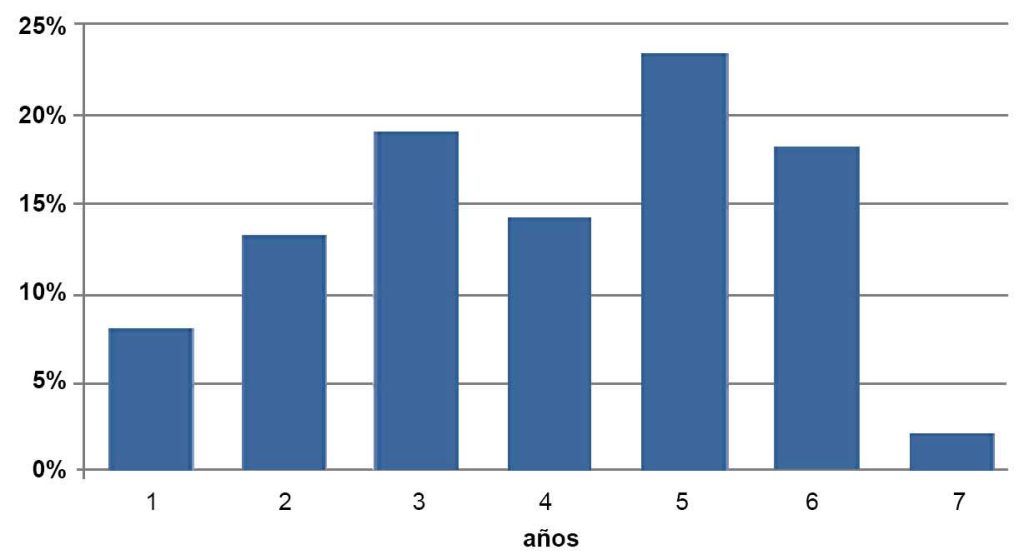

Fig. 1. Distribución de la edad de los niños.

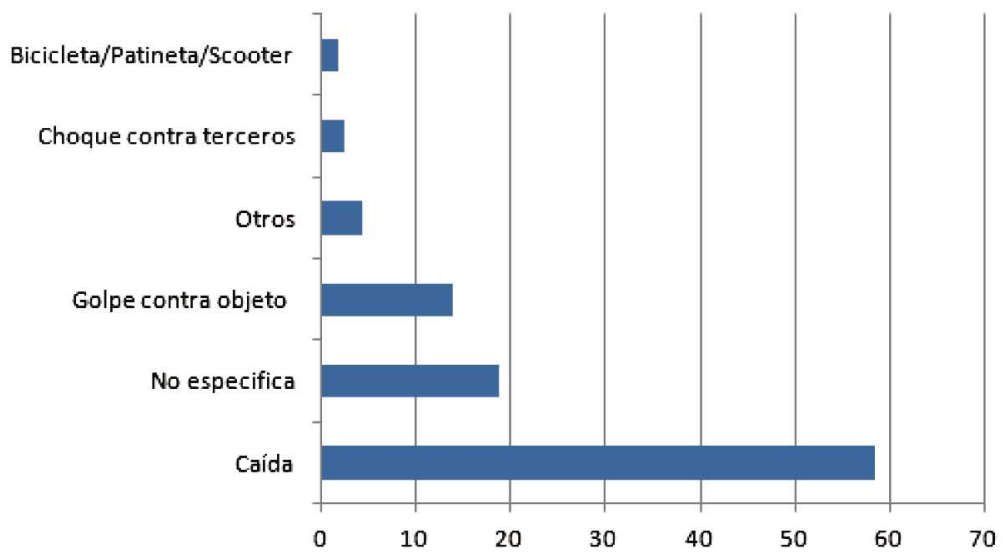

Fig. 2. Distribución de la etiología del trauma. 


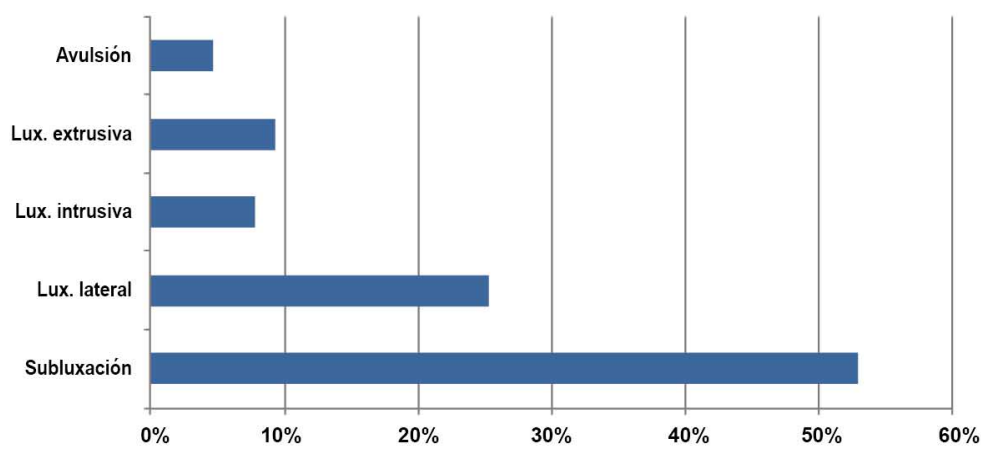

Fig. 3. Distribución de diagnóstico de trauma.

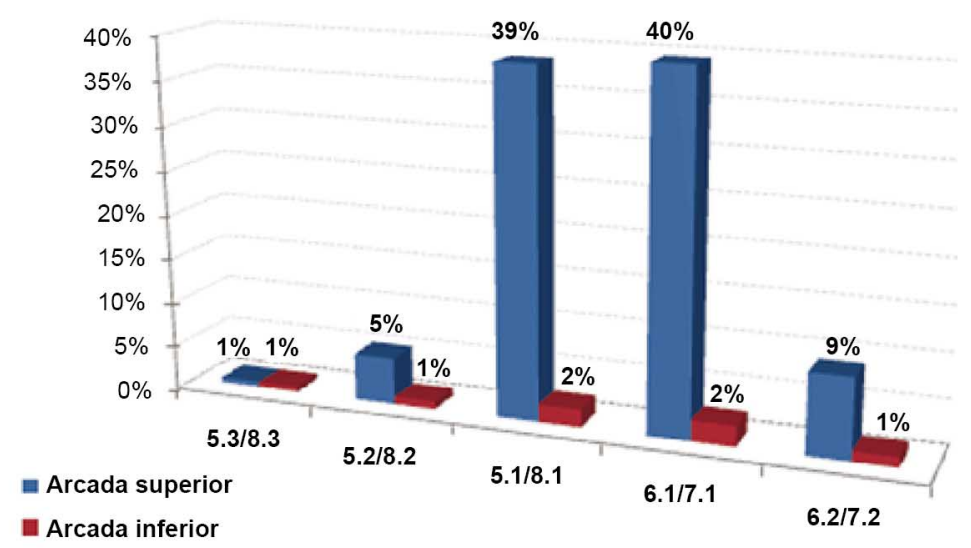

Fig. 4. Distribución del diente afectado.

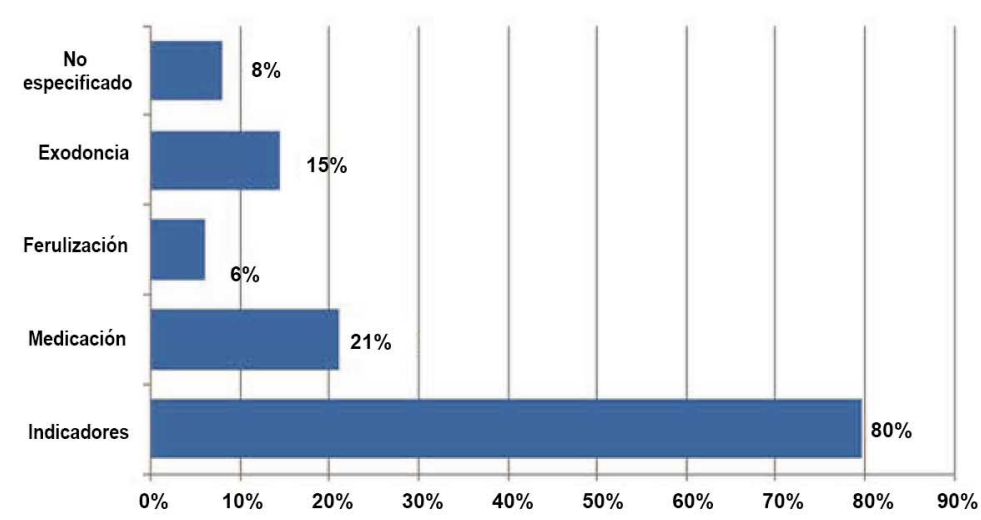

Fig. 5. Distribución del tipo de tratamiento.

A los 5 años de edad (Figura 1), se encuentra el mayor porcentaje de TDA que afecta los TSDT, sin embargo, la edad promedio en que se ven afectados los niños es de 3,9 años. Existe variada etiología para el TDA, Figura 2, que afecta los tejidos de soporte de los dientes temporales siendo el más frecuente la caída con un $59 \%$ de los casos.
El lugar donde se registra la mayor frecuencia de TDA es en los Colegios o Jardines infantiles alcanzando un $20 \%$ de total de casos, sin embargo de un $64 \%$ no registra el lugar donde ocurrió el trauma. La distribución del diagnóstico del TDA que afectan los TSDT se observa en la Figura 3, el diagnóstico más frecuente es la subluxación con un $53 \%$, por otro lado en los registros clínicos no se identificó ningún caso de concusión.

Los dientes más afectados por este tipo de trauma se concentra en los incisivos centrales superiores derecho e izquierdo, de hecho entre ambos suman el $79 \%$ de los casos. A los niños que sufren estos tipos de TDA reciben varios tratamientos, en el grafico 5 se constata la frecuencia de los diferentes tratamientos siendo más frecuente $(80 \%)$ las indicaciones de los cuidados postrauma, sin embargo, en la mayoría de los casos, no se indica sólo un tratamiento aplicado, si no que es común, la realización de tratamientos complementarios entre ellos.

\section{DISCUSIÓN}

El Centro de referencia Odontopediátrico Simón Bolívar, perteneciente al Servicio de Salud Viña del MarQuillota es el referente regional de los TDA en niños, por ello recoger datos de esta institución es representativo de la demanda de servicios por esta patología en la región.

Al relacionar en nuestros casos TDA y género, mostró una mayor frecuencia en el género masculino, esto concuerda con lo publicado por Avsar \& Topaloglu (2009), que indican una mayor predisposición por el sexo masculino, debido a actividades y juegos más agresivos documentados en edades entre los 5 y 7 años.

La edad al momento del traumatismo constató que el $57 \%$ de los pacientes tenían edades entre los 4 y 6 años al sufrir el trauma. Flores (2002), indica que el rango etario más prevalente va desde el año y medio y los dos años y medio de edad, señalan que 
ésto es debido a que en esa edad comienzan a caminar, están más activos, independientes y por ello más susceptibles. Sin embargo, en los estudios publicados por Flores se consideran todos los tipos de TDA siendo difícil compararlo con nuestros resultados los cuales sólo se refieren a los traumas que afectan los TSDT, no obstante, la falta de preocupación de los padres o tutores por una parte y que un número significativos de estos traumas son leves los hace pasar desapercibido o siendo de cierta gravedad no concurren a ningún tipo de atención profesional, ésto en parte podría explicar dichas diferencias, pues, un grupo no menor de casos quedarían sin registrar en ningún Servicio de Salud y menos son referidos a un centro de especialidad.

Nuestro estudio constato que la caída como la etiología más frecuente de TDA, similar a lo publicado por Flores y Onetto et al. (1994). Respecto al lugar del TDA, Flores y Andreasen et al. (2007) indican el hogar como el lugar más frecuente de aparición de los TDA, sin embargo nuestros resultados muestran que el lugar más frecuente donde ocurren estos accidentes es en el Colegio o Jardín Infantil, esta variable en los registros revisados, en un amplio porcentaje, no se especificó el lugar donde ocurrió el trauma, al mejorar estos registros podría variar este resultado y asimilarse a lo señalado por la literatura, pero esta diferencia también se puede explicar porque hoy en Chile tiene un aumento significativo de la cobertura de los niños que asisten a estos establecimientos educacionales, por la incorporación de la mujer al mundo laboral, mejor distribución territorial de estos establecimientos, políticas públicas para proteger la infancia, entre otras causas. Y por otro lado las jornadas que cumplen en estos jardines los niños al menos son de 6 horas diarias, que coinciden con las horas más activas de los niños. Además, el registro de éste tipo de traumas en los establecimientos educacionales es más fidedigno pues encontrándose en el colegio o jardín infantil, se debe notificar y registrar siendo obligación derivar al niño para la atención dental, la cual además esta cubierta por seguros escolares.

El diagnóstico de TDA más frecuente registrado en nuestros casos fue la subluxación, lo que coincide con Soporowski et al. (1994), los cuales consideran la subluxación como la lesión más frecuente, esta mayor frecuencia se podría explicar por una mayor flexibilidad del hueso alveolar y ligamento periodontal de los dientes temporales lo que los hace más elástico y frente a fuerzas afuncionales extremas, hace que el diente caduco se desplace.
Los dientes más afectados en esta población en estudio correspondió a los incisivos centrales superiores, lo que concuerda con los estudios de Gondim \& Moreira Neto (2005), ellos atribuyen que la disposición destacada en la arcada en una posición anterior y en ocasiones expuestos hacen más vulnerables los dientes incisivos frente a un TDA.

Respecto a los tratamientos realizados para este tipo de traumatismo, nuestros resultados resaltan una mayor frecuencia de indicaciones y control, lo cual está ligado al tipo de trauma que el niño ha sufrido (mayoritariamente subluxación), pues según la mejor evidencia disponible y las expresas sugerencias terapéuticas indicadas en las guías de practica clínica confeccionadas por el MINSAL (2007) en Chile, así como por la International Association for Dental Traumatology (2012), recomiendan no realizar acciones clínicas, sólo controlar y dar indicaciones de cuidados en especial dieta blanda y resguardo local, sin embargo, el profesional debe aplicar su juicio clínico dictado por las condiciones presentes en cada situación traumática dada. Dichas guías no garantizan resultados favorables con sólo el seguimiento de las pautas, pero utilizar los procedimientos recomendados pueden maximizar las oportunidades de éxito.

Para realizar el tratamiento se deben tener en cuenta factores importantes que determinan la selección de este como la capacidad para enfrentar la situación de emergencia así como también el tiempo que falta para el recambio del diente dañado.

Por otro lado la frecuencia y secuelas de estas lesiones podrían disminuir si se implementaran algunas medidas preventivas para el sector anterosuperior como el uso de protectores bucales y la corrección de la oclusión sobretodo en pacientes cuyos incisivos se encuentren vestibularizados, además desde el punto de vista del manejo terapéutico después del trauma sería de importancia entrenar previamente a los tutores, cuidadores, profesores, asistentes de párvulos sobre el manejo inmediato o inicial de éste tipo de lesiones.

\section{AGRADECIMIENTOS}

Al Centro Odontopediátrico Simón Bolívar, Viña del Mar, $\mathrm{V}$ región. A la Dra. María Isabel Vasquez $\mathrm{V}$. Directora del Centro Odontopediátrico Simón Bolívar. A la Dra. Sonia Gallegos Pereira y a la Dra. Jacqueline Carreño $\mathrm{Cu}$ 
ÁVILA, R. C.; CUETO, U. A. \& GONZÁLEZ, R. J. Characterization of dentoalveolar trauma that affects the supporting tissues in primary teeth. Int. J. Odontostomat., 6(2):157-161, 2012.

ABSTRACT: The purpose of pursuing this research is to evaluate the distribution of dentoalveolar trauma in time by gender, age, etiology, where the injury occurs, diagnosis of trauma, and treatment affected teeth done. The sample corresponds to 207 children benefiting from pediatric dentist referral center Simon Bolivar, ages 1 to 7 years who suffered dentoalveolar trauma of the anterior teeth during the years 2005-2007 which corresponds according to the classification proposed by Andreasen, injuries affecting the tooth supporting tissue, including: subluxation, lateral luxation, intrusive luxation, extrusive luxation and avulsion. The results obtained allow us to observe a higher percentage of trauma to the male gender with $60 \%$ being the most common age between 4 and 6 , the upper central incisors are the teeth most affected (39-40\%). The most common etiology corresponds to a $25 \%$ fall, this being more prevalent in school or kindergarten (20\%). As for the diagnosis of dentoalveolar trauma subluxation the majority are present in $53 \%$ of cases. The control and indication is the treatment most used in these dentoalveolar traumas.

KEY WORDS: dental trauma, primary teeth.

\section{REFERENCIAS BIBLIOGRÁFICAS}

Andreasen, J. O.; Andreasen, F. M. \& Andersson, L. Textbook and Color Atlas of Traumatic Injuries to the Teeth. $4^{\text {th }}$ ed. Oxford, Blackwell, 2007.

Avsar, A. \& Topaloglu, B. Traumatic tooth injuries to primary teeth of children aged 0-3 years. Dent. Traumatol., 25(3):323-7, 2009.

Flores, M. T. Traumatic injuries in the primary dentition. Dent. Traumatol., 18(6):287-98, 2002.

Gondim, J. O. \& Moreira Neto, J. J. Evaluation of intruded primary incisors. Dent. Traumatol., 21(3):131-3, 2005.

International Association for Dental Traumatology (IADT). The dental trauma guide. 2012. http:// www.dentaltraumaguide.org/

MINSAL, Ministerio de Salud. Guía clínica Urgencia Odontológica Ambulatoria. Santiago, Chile, MINSAL, 2007.

Onetto, J. E.; Flores, M. T. \& Garbarino, M. L. Dental trauma in children and adolescents in Valparaiso, Chile. Endod. Dent. Traumatol., 10(5):223-7, 1994.

Soporowski, N. J.; Allred, E. N. \& Needleman, H. L. Luxation injuries of primary anterior teeth-prognosis and related correlates. Pediatr. Dent., 16(2):96-101, 1994.
Dirección para correspondencia:

Jenniffer González Ríos

Fcaultadde Odontología

Universidad Andrés Bello

Viña del Mar

CHILE

Email: jennita107@hotmail.com

Recibido : 23-07-2012

Aceptado: $12-07-2012$ 